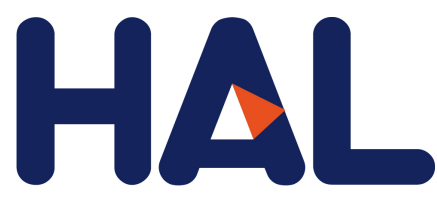

archives-ouvertes

\title{
Mononuclear Fe in N-doped carbon: computational elucidation of active sites for electrochemical oxygen reduction and oxygen evolution reactions
}

\author{
Rui Shang, Stephan Steinmann, Bo-Qing Xu, Philippe Sautet
}

\section{To cite this version:}

Rui Shang, Stephan Steinmann, Bo-Qing Xu, Philippe Sautet. Mononuclear Fe in N-doped carbon: computational elucidation of active sites for electrochemical oxygen reduction and oxygen evolution reactions. Catalysis Science \& Technology, Royal Society of Chemistry, 2020, 10 (4), pp.1006-1014. 10.1039/c9cy01935a . hal-02917724

\section{HAL Id: hal-02917724 \\ https://hal.archives-ouvertes.fr/hal-02917724}

Submitted on 19 Aug 2020

HAL is a multi-disciplinary open access archive for the deposit and dissemination of scientific research documents, whether they are published or not. The documents may come from teaching and research institutions in France or abroad, or from public or private research centers.
L'archive ouverte pluridisciplinaire HAL, est destinée au dépôt et à la diffusion de documents scientifiques de niveau recherche, publiés ou non, émanant des établissements d'enseignement et de recherche français ou étrangers, des laboratoires publics ou privés. 


\section{Mononuclear Fe in N-doped carbon: computational elucidation of active sites for electrochemical oxygen reduction and oxygen evolution reactions.}

Rui Shang ${ }^{1,2,3}$, Stephan N. Steinmann ${ }^{4}$, Bo-Qing Xu ${ }^{1 *}$, Philippe Sautet ${ }^{2,3^{*}}$

${ }^{1}$ Innovative Catalysis Program, Key Lab of Organic Optoelectronics \& Molecular Engineering, Department of Chemistry, Tsinghua University, Beijing 100084, China

${ }^{2}$ Department of Chemical and Biomolecular Engineering, University of California Los Angeles, Los Angeles, CA 90095, United States

${ }^{3}$ Department of Chemistry and Biochemistry, University of California Los Angeles, Los Angeles, CA 90095, United States

${ }^{4}$ Univ Lyon, Ecole Normale Supérieure de Lyon, CNRS Université Lyon 1, Laboratoire de Chimie UMR 5182, 46 allée d'Italie, F-69364, LYON, France

\section{Abstract}

Non-precious metal catalysts are well investigated in electrocatalysis. Fe and $\mathrm{N}$ codoped carbon $(\mathrm{Fe}-\mathrm{N}-\mathrm{C})$ catalysts have drawn a great attention due to their low cost and good performance in oxygen reduction reaction (ORR) and recently in oxygen evolution reaction (OER). Based on the recent advances of a variety of physical characterization techniques, more information about the chemical environment of the catalytic active sites has been acquired. However, due to the complexity of the catalytic material and process, the real active structures are still controversial. In this work, several active sites are proposed for $\mathrm{Fe}-\mathrm{N}-\mathrm{C}$ catalysts $\left(\mathrm{L}-\mathrm{FeN}_{\mathrm{x}}, \mathrm{x}=2\right.$ or $4, \mathrm{~L}=$ nothing, $\mathrm{O}$ or $\mathrm{OH}$ ) and their performance in electrochemical ORR and the OER are investigated. The computations are based on density functional theory (DFT), including Van der Waals interaction and solvation effect with an implicit electrolyte model. Calculations indicate that the catalytic activity of the Fe centers depends strongly on the $\mathrm{N}$ coordination number and on the presence of extra ligands like $\mathrm{OH}$ group. In particular, $\mathrm{HO}-\mathrm{FeN}_{2}$, but not $\mathrm{FeN}_{4}$, appears as the most active site. Scaling relations are obtained by connecting the free energy of potential-determining steps with the adsorption free energy of intermediates. Furthermore, three promising active sites suggested from scaling relations are studied by the more elaborate surface charging approach, which includes the influence of the applied potential and the electrolyte. The results show that the specific treatment of the influence of the applied potential has a minor influence at low potential, which is the case for ORR, but a major influence at higher potential, as 
for OER, changing the calculated overpotential by up to $0.34 \mathrm{~V}$.

\section{Introduction}

The electrochemical oxygen reduction reaction (ORR) is a key process that controls the performance of proton exchange membrane fuel cells (PEMFC). PEMFCs are promising devices to efficiently transform hydrogen and oxygen into electricity. ${ }^{1}$ However, ORR usually requires precious Pt metal as the catalyst and suffers from significant loss of energy, ${ }^{1}$ which decreases the economical attractiveness of fuel cells and limits their usage.

In order to address these problems, non-precious metal catalysts have been investigated as potential alternatives. Co-phthalocyanine was first shown to have catalytic activity for ORR. ${ }^{2}$ Inspired by that, phthalocyanine and porphyrin with various macro-cycle structures and cheap transition metals, such as $\mathrm{Fe}$ and $\mathrm{Co}$, were studied..$^{3-6}$ Then, these transition metals were doped or co-doped with $\mathrm{N}$ in graphene or carbon nanotubes (CNTs) for better conductivity and stability. ${ }^{6-8}$ Among these materials, the Fe and N codoped carbon (Fe-N-C) catalysts have attracted great attention due to their low costs and relatively high performance, ${ }^{9-15}$ but the structure of the most active site is still controversial.

On one hand, the mononuclear $\mathrm{Fe}$ in coordination with four $\mathrm{N}$ atoms $\left(\mathrm{FeN}_{4}\right)$ has been considered as the active site in most publications. ${ }^{11-13}$ Several characterizations such as extended X-ray adsorption fine structure (EXAFS), ${ }^{11} \mathrm{X}$-ray absorption near-edge structure (XANES), annular dark-field scanning transmission electron microscopy $(\mathrm{ADF}-\mathrm{STEM})^{12}$ and aberration-corrected scanning transmission electron microscopy $(\mathrm{ASTEM})^{13}$ were used to shed light on the local atomic environment of these $\mathrm{FeN}_{4}$ catalysts. On the other hand, $\mathrm{FeN}_{2}$ sites $^{14,15}$ have also been shown to have high activities with experimental evidence from high-angle annular dark-field scanning transmission electron microscopy (HADDF-STEM), EXAFS and Mossbauer spectroscopy analysis. $^{14}$ These experiment observations provide important information for identifying the real active site, with a debate between $\mathrm{FeN}_{4}$ and $\mathrm{FeN}_{2}$ sites. However, none of the aforementioned characterization methods provides an atomically precise environment around the metal. Furthermore, several sites can be present on the carbon material, rendering the determination of the "real" active site responsible for the 
measured activity difficult. We herein show that computational chemistry provides complementary insight into the nature of active site structures.

In previous theoretical studies, several models of graphene doped with iron and nitrogen have been proposed. For instance, the ORR performance of $\mathrm{FeN}_{4}$ and $\mathrm{FeN}_{2}$-doped graphene layers was compared using Density functional theory (DFT) calculations with the Perdew-Burke-Ernzerhof (PBE) functional, indicating that the electron transfer between the $3 \mathrm{~d}$ orbital of $\mathrm{Fe}$ and $2 \pi *$ orbital of $\mathrm{O}$ is beneficial to the reaction. ${ }^{16}$ The calculations also suggested that the $\mathrm{FeN}_{2+2}$ system, where the 2+2 index represents four $\mathrm{N}$ atoms that were doped in pairs on the edge of two graphene fragments, could be superior to $\mathrm{FeN}_{4}$ in extended graphene for ORR. $\mathrm{FeN}_{4}$ sites with pyridinic-type $\mathrm{N}$ or pyrrolic-type $\mathrm{N}$ were also compared and the former showed lower overpotential. ${ }^{17}$ Furthermore, an axial ligand was shown to improve the activity, with the pyridine adsorbate strengthening the $\mathrm{O}_{2}$ adsorption ${ }^{18}$ and the $\mathrm{OH}$ ligand ${ }^{19-21}$ increasing the $\mathrm{O}-\mathrm{O}$ bond scission or moderating the adsorption of adsorbates. In addition, existence of a metal-O bond was proposed to be essential in improving the activity. ${ }^{22}$ In the wellaccepted four-electron mechanism, reduction of $\mathrm{OH}$ to $\mathrm{H}_{2} \mathrm{O}$ is considered as the potential-determining step since it is shown to be the least exothermic step. When the adsorption of $\mathrm{OH}$ is weakened, the formation of $\mathrm{OOH}$ will be the potential-determining step instead. ${ }^{23}$ A volcano correlation has been found for the limiting potential versus the adsorption energy of $\mathrm{OH}$ for $\mathrm{N}$-doped graphene by relating the free energy of each step and the adsorption energy of $\mathrm{OH}^{24}$ However, only three Fe-containing structures were computed and they were rather far from the optimum potential on the volcano.

The above mentioned computational studies rely on the computational hydrogen electrode (CHE), ${ }^{25}$ which is the most popular approach to estimate the impact of the electrochemical potential. In that approach, the electron and proton are transferred together and only the chemical potential of exchanged electrons is assumed to be affected by the electrochemical potential, i.e., the electrode polarization is neglected and only neutral systems are considered. CHE is an easy-to-use zeroth order approximation that provides valuable information for determining the potentialdetermining step and generally compares well with experimental results. ${ }^{26}$ Since only neutral systems are considered, most CHE studies neglect the effect of solvation as well, ${ }^{16,18}$ even though CHE is also applicable in the presence of a solvent, e.g., Liang 
et $\mathrm{al}^{24}$ included a conductor-like screening model (COSMO) model to simulate water. As we have shown before, neglecting the explicit impact of the electrochemical potential and solvation is most dramatic when the surface dipole moment changes during a reaction, which is also reflected by a change in the workfunction of the neutral reactants, intermediates and products. ${ }^{27,28}$

The simulation of the environment of electrocatalysts, including description of the solvent, the electrolyte and the applied potential, is also indispensable for a better understanding of electrocatalytic processes. ${ }^{29}$ Beside the CHE method, a more detailed approach, named surface charging (SC), ${ }^{30}$ can be applied to model electrocatalysis. In this approach, the influence of the solvent and of the applied potential are taken into consideration, which are especially important for studying adsorbates with large dipole moments. ${ }^{31}$ A similar approach, including a continuum model of the electrolyte, ${ }^{32,33}$ has been used on $\mathrm{Pt}(111)$ to understand the influence of water molecules ${ }^{34,35}$ on ORR and also the influence of Pt particle size on the activity. ${ }^{36}$ As for the non-noble metal catalysts, SC has been applied at a selected potential for comparing the four-electron and two-electron mechanisms on $\mathrm{FeN}_{4}$ and with a $\mathrm{CN}$ ligand coordinated to $\mathrm{Fe}$ in axial direction. ${ }^{37}$ Understanding the influence of the potential on electrochemical reactions is important, the solvent and electrolyte can also provide refined energy profiles and more realistic insights to develop sites with high activity.

In this work, the Fe-N-C catalysts were investigated using cluster and periodic models in the framework of CHE approach, with the inclusion of Van der Waals interactions and an implicit solvent model. Several active site structures were set up by changing the number of $\mathrm{N}$ atoms coordinated to the Fe center and by adding an oxyl ligand (-O or $-\mathrm{OH})$ to the Fe center. In addition to the investigation on ORR, the reverse reaction, i.e., the oxygen evolution reaction (OER), was studied as well since the overpotential shifts the relevant potentials in the opposite direction on the SHE scale. Although Fedoped carbon materials ${ }^{38,39}$ have been applied in OER and experimentally found to show relatively high overpotential, ${ }^{39,40}$ it is worth exploring the active site structure and understanding the influence of the applied potential on this reaction from a fundamental perspective. Scaling relations were obtained between the reaction energy of the elementary steps and the binding energy of the $\mathrm{OH}$ fragment, for various proposed sites. Based on the obtained volcano plots for the limiting potential, $\mathrm{FeN}_{4}, \mathrm{HO}-\mathrm{FeN}_{4}$ and $\mathrm{HO}$ - 
$\mathrm{FeN}_{2}$ sites were selected and recalculated by including the influence of the potential with the SC approach as a comparison with CHE. Based on these analyses, the promising active sites are identified as $\mathrm{HO}-\mathrm{FeN}_{4}$ and $\mathrm{HO}-\mathrm{FeN}_{2}$, with overpotentials at around 0.40 and $0.60 \mathrm{~V}$ for ORR and OER, respectively. The scaling relation offers key information about the catalytically active sites and generates guidelines for the design of more promising catalyst. The present comparisons between the CHE and SC approaches shed light on understanding the impact of the potential and microenvironment of $\mathrm{Fe}$ and $\mathrm{N}$ co-doped carbon in electrocatalysis.

\section{Methods and Models}

The well-accepted mechanism for ORR and OER is the four-electron mechanism, including chemisorbed $\mathrm{OOH}, \mathrm{O}$ and $\mathrm{OH}$ as intermediates (Fig. 1). The detailed mechanism is provided in the Electronic Supplementary Information (ESI).

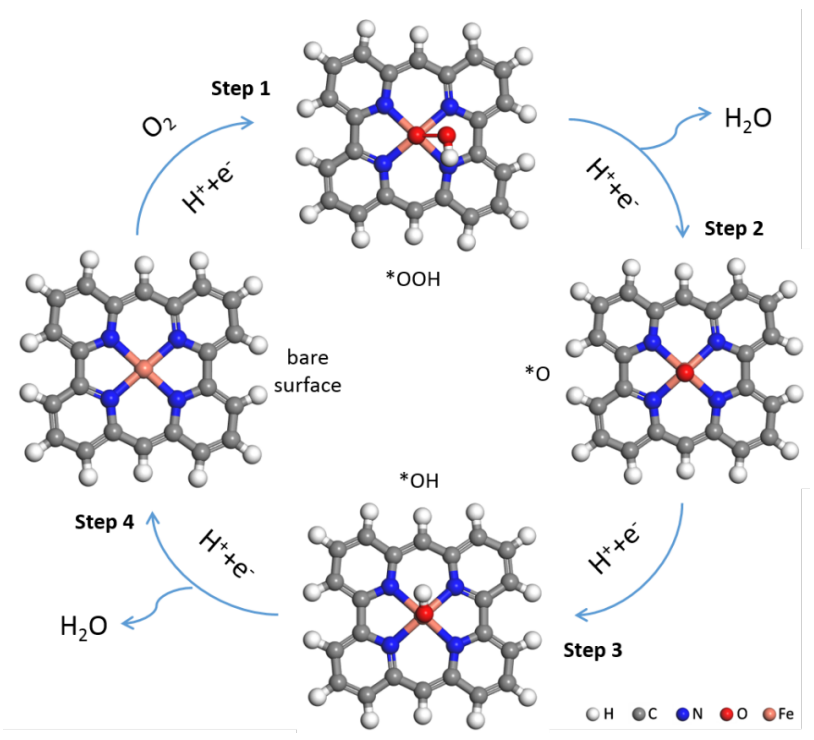

Fig. 1 Schematic presentation of the four-electron mechanism for the electrochemical ORR. A limited H-terminated cluster model of the site is used and grey, blue, orange, red and white spheres represent $\mathrm{C}, \mathrm{N}, \mathrm{Fe}, \mathrm{O}$ and $\mathrm{H}$ atoms, respectively.

All calculations were performed in the framework of spin-polarized DFT by using the Vienna $\mathrm{Ab}$ initio Simulation Package (VASP). ${ }^{41,} 42$ The generalized gradient 
approximation (GGA) in the formulation of the $\mathrm{PBE}^{43}$ functional was applied together with electron-ion interactions obtained through the Projector-Augmented Wave $(\mathrm{PAW})^{44}$ method. The cutoff energy was set as $400 \mathrm{eV}$. The convergence criteria of the energy and the force were set as $10^{-6} \mathrm{eV}$ and $0.01 \mathrm{eV} / \AA$, respectively. The Van der Waals interactions were described using the $\mathrm{dDsC}$ method. ${ }^{45,46}$ The influence of the solvent was modeled using an implicit dielectric model with the dielectric constant of water being 78.4. The electrolyte was represented using the Poisson-Boltzmann (PB) continuum approximation. The cavity surface tension was set as 0.00 and the electrolyte concentration within the linearized PB equation was set as $1.0 \mathrm{M} .^{47}$

Several structures on the graphite surface $\left(\mathrm{L}-\mathrm{FeN}_{\mathrm{x}}, \mathrm{x}=2\right.$ or $4, \mathrm{~L}=\mathrm{O}$ or $\left.\mathrm{OH}\right)$ were considered, using both cluster and periodic models (Fig. S1). For the $\mathrm{H}$ terminated cluster models, a box of $15 \times 15 \times 20 \AA$ was used and the electronic structure described at the gamma point. In the periodic models, the Fe and $\mathrm{N}$ were co-doped at a perfect graphite surface layer. For creating a $\mathrm{FeN}_{\mathrm{x}}$ site, six carbon atoms were replaced by one $\mathrm{Fe}, \mathrm{x} \mathrm{N}$ and 4-x C atoms. A $4 \times 4$ super cell with $20 \AA$ vacuum layer in the $\mathrm{z}$ direction was used. The Brillouin zone was integrated by a $3 \times 3 \times 1$ Monkhorst-Pack grid.

In the SC approach, a five-layer graphite slab was used with a $3 \times 3$ super cell, with the $\mathrm{Fe}$ and $\mathrm{N}$ co-doped in the top and bottom layer in a symmetric manner. All slabs are hence symmetric in order to avoid a net dipole and ambiguity in calculating the work functions. During the optimization, the middle layer was fixed and the other layers were allowed to relax. The solvent spacing between the slabs was set as $45 \AA$ in order to avoid overlap between the electrolyte densities on each side of it. ${ }^{47}$ The Brillouin zone was integrated by a $5 \times 5 \times 1$ Monkhorst-Pack grid.

For computations in periodic models, we first computed the energy of each spin state for each intermediate (Fig. S2), as to select the most stable spin state for the free energy diagram. Without any adsorbate, $\mathrm{FeN}_{4}$ is most stable in the triplet state, followed by the singlet (about $0.50 \mathrm{eV}$ higher) and quintet state, which is in the same sequence compared to high-level computations of iron porphyrin. ${ }^{48}$ The most stable spin states for the intermediates were chosen to plot the free energy diagram for the ORR and OER. (Fig. S3). 
Treating Van der Waals interaction and solvation effect is essential for modeling Fe and $\mathrm{N}$ co-doped electrocatalysts. Van der Waals interaction and solvation effect both stabilize $* \mathrm{OOH}, * \mathrm{O}$ and $* \mathrm{OH}$ intermediates, with a total effect of $0.30-0.50 \mathrm{eV}$, and a contribution of $40 \%$ to $60 \%$, respectively. However, a universal scaling relations were obtained with the presence or absence of these two effects, where a similar small variation of the scaling relations was observed earlier in the case of the energy difference between $\mathrm{OOH}$ and $\mathrm{OH}$ adsorption energies on precious metal surface ${ }^{49}$ when changing the exchange correlation functional.

\section{Results and discussion}

3.1 Active mononuclear Fe sites on periodic and cluster models with the CHE approach

The $\mathrm{FeN}_{4}$ structure (Fig. 2a) has been frequently considered as a potential active site for ORR. ${ }^{16,17}$ In the framework of CHE, following the four-electron mechanism of ORR, the fourth step ( ${ }^{*} \mathrm{OH}+\mathrm{H}^{+}+\mathrm{e}^{-} \rightarrow \mathrm{H}_{2} \mathrm{O}+{ }^{*}$ ) has usually been found as the potentialdetermining step. ${ }^{50}$ Our results (Fig. 2a black line) show that for this $\mathrm{FeN}_{4}$ structure, the potential-determining step depends on the level of theory. If a standard PBE exchange functional is used and the influence of the solvent is not included, the third step $\left({ }^{*} \mathrm{O}+\right.$ $\left.\mathrm{H}^{+}+\mathrm{e}^{-} \rightarrow{ }^{*} \mathrm{OH}\right)$ is found as the potential-determining step, with a difference of $0.03 \mathrm{eV}$ in free energy with respect to the fourth step $\left({ }^{*} \mathrm{OH}\right.$ to $\left.\mathrm{H}_{2} \mathrm{O}\right)$. In contrast, when Van der Waals interaction and solvation effect are included, the adsorption of $\mathrm{OH}$ is stabilized and the fourth step $\left(* \mathrm{OH}\right.$ to $\mathrm{H}_{2} \mathrm{O}$ ) becomes the potential-determining one. The overall stabilization energy of $\mathrm{OH}$ is calculated as $0.31 \mathrm{eV}$, with contributions of Van der Waals interaction and implicit solvent of 0.13 and $0.18 \mathrm{eV}$, respectively.

By looking at the reaction in the reverse direction, which corresponds to OER, the most endothermic step will be potential-determining and this is the third one $\left({ }^{*} \mathrm{O}+\mathrm{H}_{2} \mathrm{O} \rightarrow\right.$ $\left.* \mathrm{OOH}+\mathrm{H}^{+}+\mathrm{e}^{-}\right)$, in accordance with the earlier literature. ${ }^{51}$

If we get back to the ORR, since the third $(* \mathrm{O}$ to $* \mathrm{OH})$ and the fourth $\left(* \mathrm{OH}\right.$ to $\left.\mathrm{H}_{2} \mathrm{O}\right)$ steps are weakly exothermic at zero potential, and strongly endothermic at equilibrium potential for $\mathrm{FeN}_{4}$ (Fig. 2a), further adsorption and reaction of $\mathrm{O}_{2}$ on $\mathrm{O}=\mathrm{FeN}_{4}$ or $\mathrm{HO}$ $\mathrm{FeN}_{4}$ might compete with these steps. Hence, in this case, the first reaction cycle would not complete and instead $\mathrm{O}=\mathrm{FeN}_{4}$ or $\mathrm{HO}-\mathrm{FeN}_{4}$ would form as a new active site 
(structures in Fig. 3). Such catalytic cycles starting from $\mathrm{O}=\mathrm{FeN}_{4}$ or $\mathrm{HO}-\mathrm{FeN}_{4}$ have also been considered and depicted in red and blue respectively in Fig. 2 (see also Table S1 and Table S2). The first step $\left({ }^{*} \mathrm{O}_{2}+\mathrm{H}^{+}+\mathrm{e}^{-} \rightarrow{ }^{*} \mathrm{OOH}\right)$ is even more endothermic (Fig. $\mathrm{S} 4 \mathrm{a})$ in the absence of Van der Waals interaction or solvation effect, but if these are properly included, the formation of $\mathrm{O}=\mathrm{FeN}_{4}-\mathrm{OOH}$ or $\mathrm{HO}-\mathrm{FeN}_{4}-\mathrm{OOH}$ are competitive to or much more favorable than the third $(* \mathrm{O}$ to $* \mathrm{OH})$ or the fourth $\left({ }^{*} \mathrm{OH}\right.$ to $\left.\mathrm{H}_{2} \mathrm{O}\right)$ step on the bare $\mathrm{FeN}_{4}$ site (Fig. 2a). Thus, $\mathrm{O}=\mathrm{FeN}_{4}$ or $\mathrm{HO}-\mathrm{FeN}_{4}$ would more likely be the true stationary active sites if mononuclear $\mathrm{FeN}_{4}$ is assumed (Fig. 2a and Fig. S4a).

Apart from the $\mathrm{FeN}_{4}$ structure, we have also considered a different coordination situation where two $\mathrm{N}$ atoms and two graphite carbon atoms are coordinated to $\mathrm{Fe}$ (Fig. 3). ${ }^{52}$ The two $\mathrm{N}$ atoms can be either on the same side of the $\mathrm{Fe}$ center $\left(\mathrm{FeN}_{2}\right.$-cis) or on the diagonal ( $\mathrm{FeN}_{2}$-trans). With decreasing the amount of doped $\mathrm{N}$ around $\mathrm{Fe}$, the adsorption of $\mathrm{OH}$ is strengthened significantly (by 0.29 and $0.41 \mathrm{eV}$ for $\mathrm{FeN}_{2}$-cis and $\mathrm{FeN}_{2}$-trans, respectively) when comparing with $\mathrm{FeN}_{4}$ (Fig. 2), and hence the fourth step ( ${ }^{*} \mathrm{OH}$ to $\mathrm{H}_{2} \mathrm{O}$ ) becomes clearly the potential-determining one for ORR. As before, any intermediate in the cycle can be considered as a potential starting point for another cycle of ORR. In contrast to the proceeding results on $\mathrm{FeN}_{4}$, starting from $\mathrm{O}=\mathrm{FeN}_{2}$ as active site and forming $\mathrm{O}=\mathrm{FeN}_{2}-\mathrm{OOH}$ is not favorable due to the weak adsorption of $\mathrm{OOH}$ when comparing with the continuation of the first cycle and formation of $\mathrm{FeN}_{2}-\mathrm{OH}$ (Fig. $2 b c$ and Fig. S4bc). As for the adsorption of $\mathrm{O}$ on the $\mathrm{O}=\mathrm{FeN}_{2}$ sites, since the $\mathrm{C}$ atom bound to $\mathrm{Fe}$ prefers to form a $\mathrm{C}-\mathrm{O}$ bond in all possible spin states for $\mathrm{O}=\mathrm{FeN}_{2}$-trans and in the high spin state for $\mathrm{O}=\mathrm{FeN}_{2}$-cis (Fig. S5), $\mathrm{O}$ adsorption would be strong and the active site structure would be distorted. So that the formation of $* \mathrm{OOH}\left(* \mathrm{O}+\mathrm{H}_{2} \mathrm{O} \rightarrow\right.$ $\left.\mathrm{H}^{+}+\mathrm{e}^{-}+* \mathrm{OOH}\right)$ in OER can be largely hindered on $\mathrm{O}=\mathrm{FeN}_{2}$ sites. Therefore, neither $\mathrm{O}=\mathrm{FeN}_{2}$-trans nor $\mathrm{O}=\mathrm{FeN}_{2}$-cis will be discussed further as the potential steady-state active site. Altogether, the present calculations suggest that $\mathrm{HO}-\mathrm{FeN}_{2}\left(\mathrm{FeN}_{2}\right.$-cis and $\mathrm{FeN}_{2}$-trans) would most likely serve as active site for ORR (blue lines in Fig. 2bc). The increased reactivity of $\mathrm{OH}$ and $\mathrm{OOH}$ intermediates by the presence of the other $\mathrm{OH}$ ligand in trans of Fe could be associated to the well-established trans effect in inorganic chemistry ${ }^{53}$. The $\left(\mathrm{HOFeN}_{2}\right)-\mathrm{OH}$ and $\left(\mathrm{HOFeN}_{2}\right)-\mathrm{OOH}$ bonds are elongated and weakened since the trans ligands share the same d orbitals of Fe. 

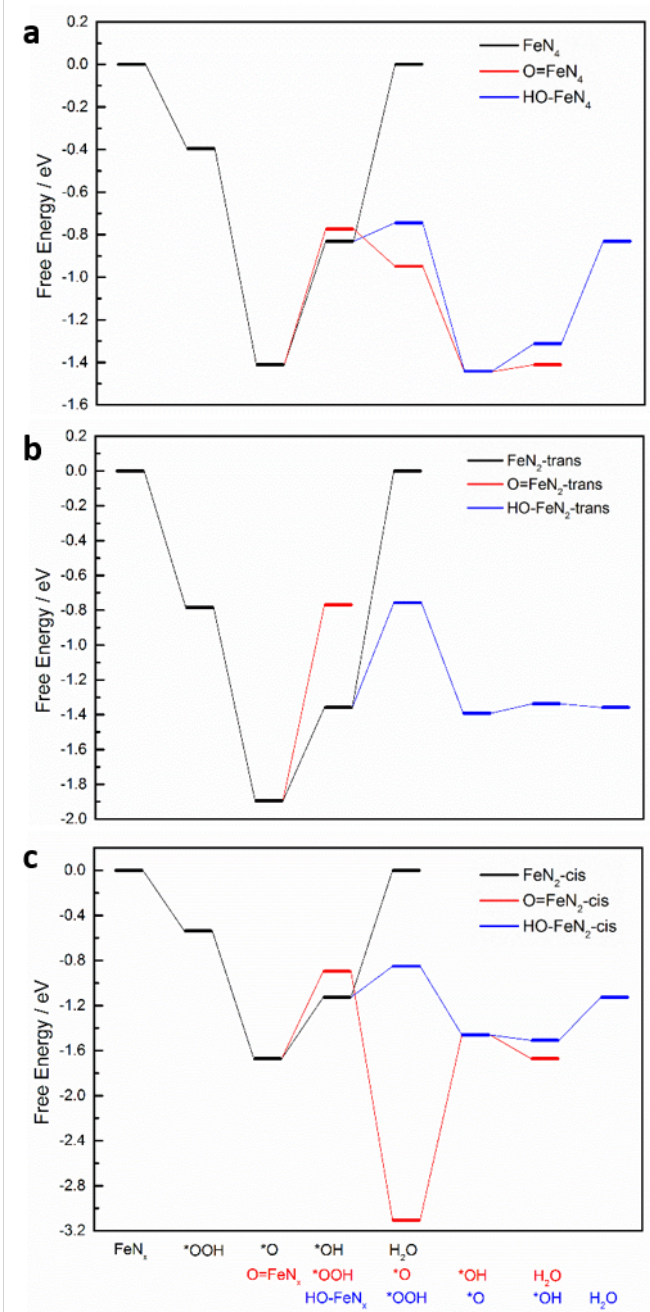

Fig. 2 Free energy diagrams for ORR assuming (a) $\mathrm{FeN}_{4}$, (b) $\mathrm{FeN}_{2}$-trans and (c) $\mathrm{FeN}_{2}$-cis as active sites, respectively. Computations include Van der Waals interaction and implicit solvent with the CHE approach at equilibrium potential $(1.23$ $\mathrm{V})$ is used. Intermediate structures of $\mathrm{O}=\mathrm{FeN}_{\mathrm{x}}$ or $\mathrm{HO}-\mathrm{FeN}_{\mathrm{x}}(\mathrm{x}=2$ or 4) are also considered as active sites to start a second ORR cycle as shown with the red and blue lines and labels, respectively.

Our computations using the periodic and cluster models of the active sites provide 
similar results and conclusions that the presence of extra $\mathrm{OH}$ ligand and modification of $\mathrm{N}$ coordination number around Fe could largely influence the activity (Fig. S6). From the geometrical perspective, the $\mathrm{FeN}_{\mathrm{x}}(\mathrm{x}=2$ or 4$)$ doped carbon cluster structures with $\mathrm{H}$ atoms termination tend to bend when $\mathrm{O}, \mathrm{OH}$ and, particularly, the $\mathrm{OOH}$ is adsorbed, which potentially due to relative flexibility of the structure and tension on the edge. Nevertheless, the presence of a hydroxyl ligand $\mathrm{HO}-\mathrm{FeN}_{\mathrm{x}}$ would help to stabilize the intermediate structures in cluster models as the same in periodic models. The adsorption of $\mathrm{O}$ on $\mathrm{O}=\mathrm{FeN}_{2}$ sites in cluster models would also distort the structure and thus were not considered further as potential active sites. Quantitatively, a weaker adsorption of $\mathrm{OH}$ on the cluster models (by $0.2 \mathrm{eV}$ ) was observed, due to an approximate description of the graphene electronic structure.

\subsection{Scaling relations for different proposed active sites.}

The comparison of the ORR activity for the seven active sites specified in this study $\left(\mathrm{FeN}_{4}, \mathrm{FeN}_{2}\right.$-cis, $\mathrm{FeN}_{2}$-trans, $\mathrm{HO}-\mathrm{FeN}_{4}, \mathrm{HO}-\mathrm{FeN}_{2}$-cis, $\mathrm{HO}-\mathrm{FeN}_{2}$-trans and $\mathrm{O}=\mathrm{FeN}_{4}$ ) can be made more universal by constructing scaling relations for adsorption free energies and volcano plots for the limiting potential. Since the fourth step $\left(* \mathrm{OH}\right.$ to $\left.\mathrm{H}_{2} \mathrm{O}\right)$ is potential-determining, the adsorption free energy of $\mathrm{OH}$ is a key parameter, and therefore used as a descriptor for the adsorption free energy of all other intermediates. ${ }^{17}$

Fig. 3a shows the calculated potential as a function of the adsorption free energy of $\mathrm{OH}$ $\left(\Delta \mathrm{G}{ }^{*} \mathrm{OH}\right)$ for each elementary step in ORR. The fourth step ( ${ }^{*} \mathrm{OH}$ to $\mathrm{H}_{2} \mathrm{O}$ ) is usually considered as the potential-determining step, however when the adsorption of $\mathrm{OH}$ is weakened, the formation of $\mathrm{OOH}$ will be the potential-determining step instead. ${ }^{23}$ The actual output potential will correspond to the lowest envelope. $\Delta \mathrm{G} * \mathrm{OH}$ increases by following the sequence $\mathrm{FeN}_{2}$-trans $<\mathrm{FeN}_{2}$-cis $<\mathrm{FeN}_{4}<\mathrm{HO}-\mathrm{FeN}_{4}<\mathrm{HO}-\mathrm{FeN}_{2}$-cis $<$ $\mathrm{O}=\mathrm{FeN}_{4}<\mathrm{HO}-\mathrm{FeN}_{2}$-trans. In the case of highly stable $\mathrm{OH}$ adsorption (left part of Fig. 3a), the fourth step ( ${ }^{*} \mathrm{OH}$ to $\mathrm{H}_{2} \mathrm{O}$ in magenta) appears to be potential-determining step The highest limiting potential and hence the lowest overpotential $(0.30 \mathrm{~V})$ is obtained at the crossing point where $\Delta \mathrm{G} * \mathrm{OH}$ is $0.93 \mathrm{eV}$.

The bare $\mathrm{FeN}_{4}$ site, often proposed as the active site for ORR in the literature, ${ }^{11,12}$ is on 
the left of the diagram, far from the optimum, with a large calculated overpotential of $0.83 \mathrm{~V}$. The bare $\mathrm{FeN}_{2}$ sites adsorb $\mathrm{OH}$ even more strongly than $\mathrm{FeN}_{4}$, which is not favorable for ORR. In the preceding section, we have shown that the real steady state active site would bear an extra $\mathrm{OH}$ ligand. This $-\mathrm{OH}$ ligand significantly weakens the adsorption strength of the extra $* \mathrm{OH}$ intermediate and places the sites in the favorable region of the volcano. The best site is thus determined by the present calculations to be HO-FeN $\mathrm{N}_{2}$, where $\mathrm{Fe}$ is coordinated with two $\mathrm{N}$ and two $\mathrm{C}$ atoms, and stabilized by an extra $\mathrm{OH}$ ligand. In the submission process on the present manuscript, other works appeared in the literature underlining the importance of existing $\mathrm{OH}$ ligand ${ }^{19}$, 20, either from the dissociation of $\mathrm{H}_{2} \mathrm{O}$ or from the basic media. Our work suggests that the active sites with extra $\mathrm{OH}$ ligand would be formed in situ during the reaction. Also compared with the further $\mathrm{OH}$ adsorption on the same side of the already present $\mathrm{OH}$ ligand ${ }^{20}$, adsorption on the opposite side of the Fe center, as considered here, is weakened by the trans effect.

The same treatment can be applied to the OER, by considering the reverse steps. The third step $\left({ }^{*} \mathrm{O}\right.$ to $\left.{ }^{*} \mathrm{OOH}\right)$ is generally considered as the potential-determining step in OER, even though the second step $\left({ }^{*} \mathrm{OH}\right.$ to $\left.{ }^{*} \mathrm{O}\right)$ could also be limiting. ${ }^{51}$ We selected $\Delta \mathrm{G}_{2}=\Delta \mathrm{G} *_{\mathrm{O}}-\Delta \mathrm{G} *_{\mathrm{OH}}$ as energy descriptor ${ }^{54}$ to plot the scaling relation (Fig. 4 ). $\Delta \mathrm{G}_{3}$ shows a good quality linear relation to $\Delta \mathrm{G}_{2}$. Since we are now in electrolysis conditions, the diagram should be read differently where the higher potential envelope is the limiting potential. Without any additional ligand, the $\mathrm{FeN}_{\mathrm{x}}$ sites $(\mathrm{x}=2$ or 4 , square symbols) generate large overpotentials (Fig. 4 and Fig. S8). However, with an -OH or -O ligand, the overpotential decreases dramatically (circles and triangle stand for HO$\mathrm{FeN}_{\mathrm{x}}$ and $\mathrm{O}=\mathrm{FeN}_{4}$, respectively in Fig. 4). The optimal overpotential is $0.32 \mathrm{~V}$ for OER. The promising sites for OER are $\mathrm{O}=\mathrm{FeN}_{4}, \mathrm{HO}-\mathrm{FeN}_{2}$-cis and $\mathrm{HO}-\mathrm{FeN}_{4}$. $\mathrm{HO}-\mathrm{FeN}_{2}$-cis hence appears as an efficient active both for OER and ORR, leading to small overpotential in each case. 

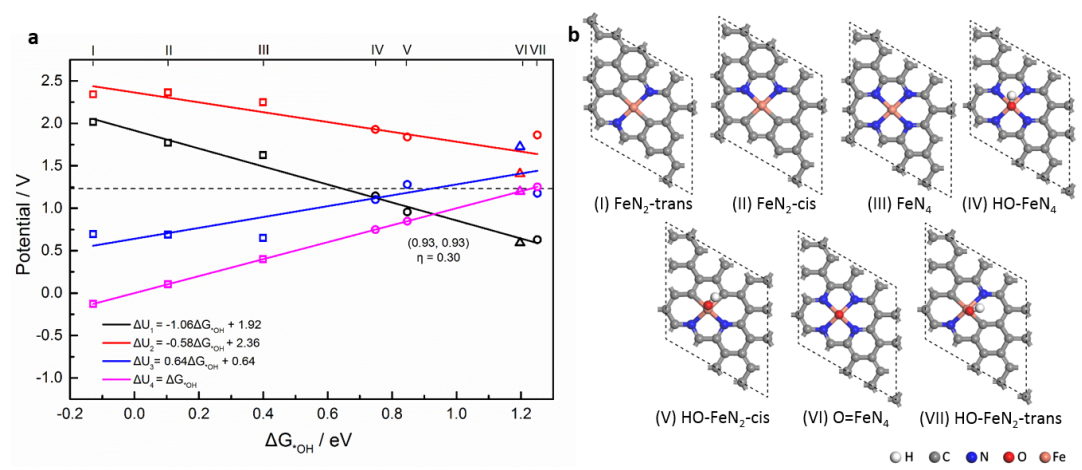

Fig. 3 (a) Potential scaling relations as a function of $\mathrm{OH}$ adsorption free energy for ORR using PBE with Van der Waals interaction and solvation effect included. The energies are based on the most stable spin state of each intermediate using periodic models. The free energy of the first, second, third and the fourth step of the four-electron mechanism, namely formation of ${ }^{*} \mathrm{OOH},{ }^{*} \mathrm{OOH}$ to ${ }^{*} \mathrm{O}$, ${ }^{*} \mathrm{O}$ to ${ }^{*} \mathrm{OH}$ and ${ }^{*} \mathrm{OH}$ to $\mathrm{H}_{2} \mathrm{O}$, are shown in black, red, blue and magenta lines, respectively. The square, the circle and the triangle symbols stand for $\mathrm{FeN}_{\mathrm{x}}, \mathrm{HO}-\mathrm{FeN}_{\mathrm{x}}\left(\mathrm{x}=2\right.$ or 4 ) and $\mathrm{O}=\mathrm{FeN}_{4}$, respectively. (b) The geometry of different periodic active site models, which are listed in the sequence of increasing $\mathrm{OH}$ adsorption free energy. Grey, blue, orange, red and white spheres represent $\mathrm{C}, \mathrm{N}, \mathrm{Fe}, \mathrm{O}$ and $\mathrm{H}$ atoms, respectively. The structures are labeled I-VII in (b) and their corresponding performance are shown in (a).

\subsection{Including the influence of the potential with the SC approach}

From the proceeding scaling relations, three promising sites were chosen $\left(\mathrm{FeN}_{4}, \mathrm{HO}-\right.$ $\mathrm{FeN}_{4}$ and $\mathrm{HO}-\mathrm{FeN}_{2}$-cis) and were subjected to more detailed computation by taking explicitly the potential into account with the SC approach (Fig. S9). 
In order to understand the influence of the potential on each step, we first looked into the adsorption energy of intermediates. Unlike in the CHE approach, where the potential has no influence on the adsorption energies (left panel of Fig. 5, dash line), the adsorption energy varies as a function of applied potential (left panel of Fig. 5, solid line) in the SC approach. The adsorption energy of formally neutral intermediates is obtained with the same equation as in the CHE approach (equation 9-11 in the ESI), where $\mathrm{H}_{2}$ and $\mathrm{H}_{2} \mathrm{O}$ are taken as energy reference for the adsorbates at constant charge. However, the intermediates are considered at different potentials. Generally, the change (in eV per $\mathrm{V}$ ) is largest for the ${ }^{*} \mathrm{O}$ adsorbate on all selected sites followed by the ${ }^{*} \mathrm{OOH}$ and $* \mathrm{OH}$ species. This is in agreement with ${ }^{*} \mathrm{O}$ featuring the highest surface dipole moment and, thus, the most positive workfunction (about $1 \mathrm{~V}$ higher than the bare surface, see ESI). Adsorption of $\mathrm{O}$ would be destabilized by $0.30,0.32$ and $0.43 \mathrm{eV}$ per $\mathrm{V}$ on $\mathrm{FeN}_{4}, \mathrm{HO}-\mathrm{FeN}_{4}$ and $\mathrm{HO}-\mathrm{FeN}_{2}$-cis, respectively, which are far from negligible. To be noted, the crossing point between the $\mathrm{SC}$ and $\mathrm{CHE}$ adsorption energies occurs at different potential.

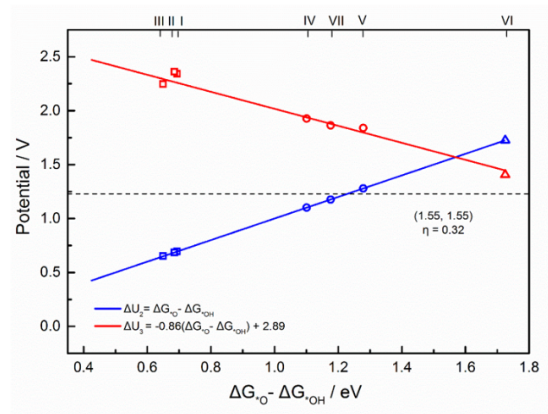

Fig. 4 Scaling relations for the limiting potential of each step as a function of the difference between $\mathrm{O}$ and $\mathrm{OH}$ adsorption free energy for OER using PBE with Van der Waals interaction in implicit solvent. The energies are based on the most stable spin state of each intermediate using the periodic models. The square, the circle and the triangle symbols stand for $\mathrm{FeN}_{\mathrm{x}}, \mathrm{HO}-\mathrm{FeN} \mathrm{N}_{\mathrm{x}} \mathrm{x}=2$ or 4) and $\mathrm{O}=\mathrm{FeN}_{4}$, respectively (I: $\mathrm{FeN}_{2}$-trans, II: $\mathrm{FeN}_{2}$-cis, III: $\mathrm{FeN}_{4}$, IV: HO-FeN 4 , V: HO-FeN ${ }_{2}$-cis, VI: $\mathrm{O}=\mathrm{FeN}_{4}$, VII: $\mathrm{HO}-\mathrm{FeN}_{2}$-trans). 

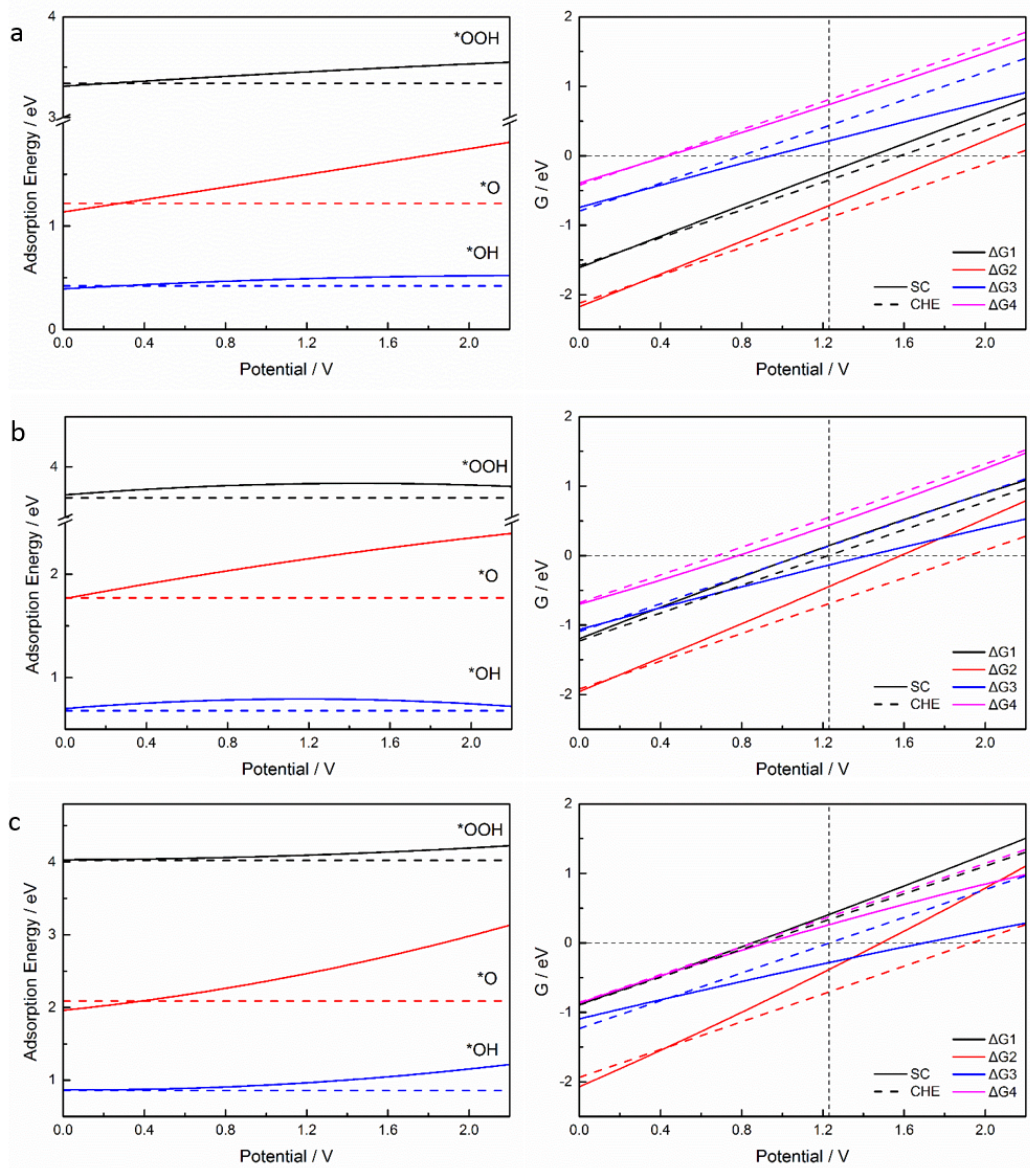

Fig. 5 The adsorption energy of intermediate ${ }^{*} \mathrm{OOH}$ (black), ${ }^{*} \mathrm{O}$ (red) and ${ }^{*} \mathrm{OH}$ (blue) as a function of potential (left). The solid and the dash line stand for the SC and CHE results. The free energy with CHE or SC approaches for the various steps of ORR as a function of potential (right). The potential range is from 0.00 to $2.20 \mathrm{~V}$. $\Delta \mathrm{G} 1$ to $\Delta \mathrm{G} 4$ represent the free energy of the first, second, third and fourth step of the four-electron mechanism, namely formation of ${ }^{*} \mathrm{OOH},{ }^{*} \mathrm{OOH}$ to ${ }^{*} \mathrm{O},{ }^{*} \mathrm{O}$ to ${ }^{*} \mathrm{OH}$ and ${ }^{*} \mathrm{OH}$ to $\mathrm{H}_{2} \mathrm{O}$, with black, red, blue and magenta lines, respectively. Considered active sites are (a) $\mathrm{FeN}_{4}$, (b) $\mathrm{HO}-\mathrm{FeN}_{4}$ and (c) $\mathrm{HO}-\mathrm{FeN}_{2}$-cis.

After determining how the potential affects adsorption energies of each intermediate, the influence of potential on the free energy of the corresponding reaction step can be obtained (Fig. 5, right panels). As formally one electron is transferred in each step, not only the adsorption energies of the intermediates, but also their charge as a function of the potential comes into play since it modulates the effective number of electrons 
transferred. Generally, the larger the influence of the potential on the energy of intermediates, the larger the deviations from the CHE results, unless the intermediate energy shift equivalently under potential. The dashed lines have a slope of 1.0 for each free energy step within the CHE approach (Fig. 5, right panels) while the solid line of $\mathrm{SC}$ can have a slope different from unity. The detailed relations between the free energy and injected charge as a function of potential are shown in the SI (Fig. S10 - Fig. S15).

The first step is only linked with $\mathrm{OOH}$ adsorption energy, and hence shows a negligible deviation for its reaction energy $\Delta \mathrm{G} 1$ between $\mathrm{CHE}$ and $\mathrm{SC}$ approaches for $\mathrm{HO}-\mathrm{FeN}_{2}-$ cis (Fig. 5c, right panel). Larger differences are obtained for $\mathrm{FeN}_{4}$ and $\mathrm{HO}-\mathrm{FeN}_{4}$, with a decrease of $\Delta \mathrm{G} 1$ at equilibrium potential by $0.12 \mathrm{eV}$ with the SC approach. The second $(* \mathrm{OOH}$ to $* \mathrm{O})$ and the third $(* \mathrm{O}$ to $* \mathrm{OH})$ steps involve $* \mathrm{O}$ as an intermediate and hence are generally markedly affected by the potential, with, for example, a decrease of reaction energy at equilibrium potential for the second step $\left(* \mathrm{OOH}\right.$ to $\left.{ }^{*} \mathrm{O}\right)$ by $0.32 \mathrm{eV}$ for $\mathrm{HO}-\mathrm{FeN}_{2}$-cis. This is mitigated in cases where $\mathrm{OOH}$ and $\mathrm{O}$ adsorption energy evolve in the same way $\left(\mathrm{FeN}_{4}, \mathrm{HO}-\mathrm{FeN}_{4}\right)$. Since the fourth step $\left({ }^{*} \mathrm{OH}\right.$ to $\left.\mathrm{H}_{2} \mathrm{O}\right)$ only depends on $\mathrm{OH}$ adsorption which is weakly potential dependent, it shows a small deviation between $\mathrm{CHE}$ and SC approaches. Note that for each step, there is a potential value where the $\mathrm{CHE}$ and the $\mathrm{SC}$ free energy cross, providing a zone of potentials where results from both approaches coincide.

Based on these graphs, the fourth step $\left({ }^{*} \mathrm{OH}\right.$ to $\left.\mathrm{H}_{2} \mathrm{O}\right)$ is the potential-determining step on all selected sites, since it is the first one to become endothermic upon potential increase. The crossing point at $\Delta \mathrm{G}_{4}=0$ determines the output potential, and its deviation from the ideal redox-potential gives the overpotential. Since the fourth step $\left({ }^{*} \mathrm{OH}\right.$ to $\mathrm{H}_{2} \mathrm{O}$ ) is only weakly affected by the applied potential, the calculated overpotentials by the SC approach $\left(0.79,0.45\right.$ and $0.38 \mathrm{~V}$ for $\mathrm{FeN}_{4}, \mathrm{HO}-\mathrm{FeN}_{4}$ and $\mathrm{HO}-\mathrm{FeN}_{2}$-cis, respectively) are close to the CHE value $(0.81,0.53$ and $0.37 \mathrm{~V})$. However, SC has significant impacts on other steps, which become important if we change from ORR to OER. In this case, the third step $(* \mathrm{O}$ to $* \mathrm{OOH}$, the reverse of the second step in ORR) becomes the potential-determining step and a large influence of the potential in the SC approach is shown, especially at high potential relevant to this reaction. The calculated overpotentials for OER with SC $\left(0.59,0.35\right.$ and $0.47 \mathrm{~V}$ for $\mathrm{FeN}_{4}, \mathrm{HO}-\mathrm{FeN}_{4}$ and $\mathrm{HO}-$ $\mathrm{FeN}_{2}$-cis, respectively) show a strong decrease compared to CHE values $(0.89,0.69$ 
and $0.65 \mathrm{~V}$ ) by up to $0.34 \mathrm{~V}$ on the $\mathrm{HO}-\mathrm{FeN}_{4}$ site (Table S4 and Table S5). One point to note is that the most endothermic step is changing versus potential on $\mathrm{HO}-\mathrm{FeN}_{2}$-cis, which is reflected by the change of potential-determining step from the $(* \mathrm{O}$ to $* \mathrm{OOH})$ step with CHE approach to the $(* \mathrm{OH}$ to $* \mathrm{O})$ step when using the SC approach. In contrast to ORR, the potential-determining step in OER involves the ${ }^{*} \mathrm{O}$ intermediate. The adsorption energy of $* \mathrm{O}$ is markedly potential dependent, which explains the important correction brought by the SC approach for OER. In a nutshell, the potential has contrasted influence on the adsorption energy of intermediates, hence on reaction steps and on overpotential.

As noted earlier, ${ }^{27,55,56}$ the qualitative impact of SC compared to CHE can be predicted by comparing the workfunction changes for a given elementary reaction step (see Fig. S16). For quantitative predictions, the capacitance (and its change) is, however, required. ${ }^{28}$ In particular, we find that even though the $\mathrm{FeN}_{4}, \mathrm{HO}-\mathrm{FeN}_{4}$ and $\mathrm{HO}-\mathrm{FeN}_{2}$ systems are very closely related, the capacitance of $\mathrm{FeN}_{4}$ is almost $50 \%$ smaller than for the other two systems and, thus, the impact of the change in workfunction is approximately halved for $\mathrm{FeN}_{4}$ compared to $\mathrm{HO}-\mathrm{FeN}_{4}$ or $\mathrm{HO}-\mathrm{FeN}_{2}$, indicating that the constant capacitance approximation would be very rough and should not be applied when detailed insights and precise energetic predictions are sought after. ${ }^{57}$

\section{Conclusions}

Several Fe-N-C active sites for Fe and $\mathrm{N}$ co-doped carbon $(\mathrm{L}-\mathrm{FeN} \mathrm{x}, \mathrm{x}=2$ or $4, \mathrm{~L}=$ nothing, $\mathrm{O}$ or $\mathrm{OH})$ were considered for a computational study of the catalytic mechanism of ORR and OER. The adsorption free energies of $\mathrm{OOH}, \mathrm{O}$ and $\mathrm{OH}$ are strongly affected by changes in the coordination of the Fe center, either a modification of the number of $\mathrm{N}$ and $\mathrm{C}$ atoms coordinated to $\mathrm{Fe}$ in the equatorial plane, or addition of $\mathrm{O}$ or $\mathrm{OH}$ ligand in the axial direction. In general, the coordination of an -OH ligand can largely decrease the adsorption of $\mathrm{OH}$ on the opposite side of the Fe center, and thus reduce the overpotential, which is crucial for the moderate adsorption of $\mathrm{OH}$ in the catalytic cycle and the activity of the $\mathrm{FeN}_{\mathrm{x}}$ site. From the scaling relations, the optimal potential values were obtained at an applied potential of $0.93 \mathrm{~V}$ and $1.55 \mathrm{~V}$ for ORR and OER, corresponding to an overpotential of $0.30 \mathrm{~V}$ and $0.32 \mathrm{~V}$ respectively. The description of Van der Waals interactions and the effect of the solvent do not change the scaling relations and limiting potential volcano plot, but considerably affect the $\mathrm{OH}$ 
adsorption free energy and hence the determination of the best catalyst structure.

The promising active sites with low overpotential $\left(\mathrm{HO}-\mathrm{FeN} \mathrm{N}_{4}\right.$ and $\mathrm{HO}-\mathrm{FeN} \mathrm{N}_{2}$ ) were further studied by the SC approach, which includes the influence of the applied potential, solvent and electrolyte. The potential was shown to affect the adsorption energy of intermediates, especially on $* \mathrm{O}$ with a destabilization of up to $0.43 \mathrm{eV} / \mathrm{V}$. Overall, the influence of an explicit treatment of the potential appears minor for ORR, but a large influence was observed in OER with an overpotential reduced by up to 0.34 $\mathrm{V}$. Thus, the explicit treatment of the potential does have an influence on the free energy steps but the impact on the limiting potential depends on the reaction.

In conclusion, this work provides key insight on the optimal structure of the catalytic active site for ORR and OER on Fe-N-C catalysts from a theoretical perspective, which is important for the design of new efficient catalyst. Our comparison between the CHE and SC approaches illustrates the difference between these two approaches and offer instructions for a method choice in future studies.

\section{Conflicts of interest}

There are no conflicts to declare.

\section{Acknowledgements}

The authors would like to thank China Scholarship Council (CSC) and Tsinghua University (20131089311) for the financial support. This work used computational and storage services associated with the Hoffman2 shared cluster provided by UCLA Institute for Digital Research and Education Group.

\section{References}

1 J. Wu and H. Yang, Acc. Chem. Res., 2013, 46, 1848-1857.

2 R. Jasinski, Nature, 1964, 201, 1212-1213.

3 Z. Zhang, M. Dou, J. Ji and F. Wang, Nano Energy, 2017, 34, 338-343.

4 R. Chen, H. Li, D. Chu and G. Wang, J. Phys. Chem. C, 2009, 113, 20689-20697.

5 S. A. Mamuru, K. I. Ozoemena, T. Fukuda, N. Kobayashi and T. Nyokong, Electrochim. Acta, 2010, 55, 6367-6375.

6 R. Cao, R. Thapa, H. Kim, X. Xu, M. Gyu Kim, Q. Li, N. Park, M. Liu and J. Cho, Nat. Commun., 2013, 4, 2076.

7 H. R. Byon, J. Suntivich and Y. Shao-Horn, Chem. Mater., 2011, 23, 3421-3428. 
10 A. Iannaci, B. Mecheri, A. D'Epifanio, M. J. Lázaro Elorri and S. Licoccia, Int. J. Hydrog. Energy, 2016, 41, 19637-19644.

Z. Miao, X. Wang, M.-C. Tsai, Q. Jin, J. Liang, F. Ma, T. Wang, S. Zheng, B.-J. Hwang, Y. Huang, S. Guo and Q. Li, Adv. Energy Mater., 2018, 8, 1801226.

H. Fei, J. Dong, Y. Feng, C. S. Allen, C. Wan, B. Volosskiy, M. Li, Z. Zhao, Y. Wang, H. Sun, P. An W. Chen, Z. Guo, C. Lee, D. Chen, I. Shakir, M. Liu, T. Hu, Y. Li, A. I. Kirkland, X. Duan and Y. Huang, Nat. Catal., 2018, 1, 63-72.

H. T. Chung, D. A. Cullen, D. Higgins, B. T. Sneed, E. F. Holby, K. L. More and P. Zelenay, Science, 2017, 357, 479-484.

H. Shen, E. Gracia-Espino, J. Ma, H. Tang, X. Mamat, T. Wagberg, G. Hu and S. Guo, Nano Energy, 2017, 35, 9-16.

C. Zhu, Q. Shi, B. Z. Xu, S. Fu, G. Wan, C. Yang, S. Yao, J. Song, H. Zhou, D. Du, S. P. Beckman, D. Su and Y. Lin, Adv. Energy Mater., 2018, 8, 1801956.

16 S. Kattel, P. Atanassov and B. Kiefer, Phys. Chem. Chem. Phys., 2014, 16, 13800-13806.

17 F. Calle-Vallejo, J. I. Martinez and J. Rossmeisl, Phys. Chem. Chem. Phys., 2011, 13, 15639-15643.

18 C. E. Szakacs, M. Lefevre, U. I. Kramm, J. P. Dodelet and F. Vidal, Phys. Chem. Chem. Phys., 2014, 16, 13654-13661.

M. Xiao, Y. Chen, J. Zhu, H. Zhang, X. Zhao, L. Gao, X. Wang, J. Zhao, J. Ge, Z. Jiang, S. Chen, C. Liu and W. Xing, J. Am. Chem. Soc., 2019, 141, 17763-17770. H. B. Tao, J. Zhang, J. Chen, L. Zhang, Y. Xu, J. G. Chen and B. Liu, J. Am. Chem. Soc., 2019, 141 13803-13811.

22 X. Chen, L. Yu, S. Wang, D. Deng and X. Bao, Nano Energy, 2017, 32, 353-358.

23 F. Calle-Vallejo, J. Tymoczko, V. Colic, Q. H. Vu, M. D. Pohl, K. Morgenstern, D. Loffreda, P. Sautet, W. Schuhmann and A. S. Bandarenka, Science, 2015, 350, 185-189.

24 W. Liang, J. Chen, Y. Liu and S. Chen, ACS Catal., 2014, 4, 4170-4177.

25 J. K. Nørskov, J. Rossmeisl, A. Logadottir, L. Lindqvist, J. R. Kitchin, T. Bligaard and H. Jónsson, J. Phys. Chem. B, 2004, 108, 17886-17892.

J. Greeley, I. E. Stephens, A. S. Bondarenko, T. P. Johansson, H. A. Hansen, T. F. Jaramillo, J. Rossmeisl, I. Chorkendorff and J. K. Norskov, Nat. Chem., 2009, 1, 552-556.

27 S. N. Steinmann, C. Michel, R. Schwiedernoch, J. S. Filhol and P. Sautet, Chemphyschem, 2015, 16, 2307-2311.

S. N. Steinmann, C. Michel, R. Schwiedernoch and P. Sautet, Phys. Chem. Chem. Phys., 2015, 17, 13949-13963.

29 S. N. Steinmann, Z. Y. Wei and P. Sautet, Proc. Natl. Acad. Sci. U. S. A., 2019, 116, 7611-7613.

30 C. D. Taylor, S. A. Wasileski, J.-S. Filhol and M. Neurock, Phys. Rev. B, 2006, 73.

31 J. Rossmeisl, J. K. Norskov, C. D. Taylor, M. J. Janik and M. Neurock, J. Phys. Chem. B, 2006, 110, 21833-21839.

32 A. J. Garza, A. T. Bell and M. Head-Gordon, ACS Catal., 2018, 8, 1490-1499.

33 S. N. Steinmann, C. Michel, R. Schwiedernoch, M. Wu and P. Sautet, J. Catal., 2016, 343, 240247.

34 R. Jinnouchi and A. B. Anderson, Phys. Rev. B, 2008, 77, 245417. 

861.

36 G. F. Wei and Z. P. Liu, Phys. Chem. Chem. Phys., 2013, 15, 18555-18561.

37 J. Sun, Y. H. Fang and Z. P. Liu, Phys. Chem. Chem. Phys., 2014, 16, 13733-13740.

T. Gao, C. Zhou, Y. Zhang, Z. Jin, H. Yuan and D. Xiao, J. Mater. Chem. A, 2018, 6, 21577-21584.

X. Zeng, J. Shui, X. Liu, Q. Liu, Y. Li, J. Shang, L. Zheng and R. Yu, Adv. Energy Mater., 2018, 8, 1701345.

M. Wu, Q. Wei, G. Zhang, J. Qiao, M. Wu, J. Zhang, Q. Gong and S. Sun, Adv. Energy Mater., 2018, 8, 1801836.

41 G. Kresse and J. Furthmüller, Comput. Mater. Sci., 1996, 6, 15-50.

42 G. Kresse and J. Hafner, Phys. Rev. B: Condens. Matter, 1993, 47, 558-561.

43 J. P. Perdew, K. Burke and M. Ernzerhof, Phys. Rev. Lett., 1996, 77, 3865-3868.

$44 \quad$ G. Kresse and D. Joubert, Phys. Rev. B, 1999, 59, 1758-1775.

45 S. N. Steinmann and C. Corminboeuf, J. Chem. Theory Comput., 2011, 7, 3567-3577.

46 S. N. Steinmann and C. Corminboeuf, J. Chem. Phys., 2011, 134, 044117.

47 S. N. Steinmann and P. Sautet, J. Phys. Chem. C, 2016, 120, 5619-5623.

48 Q. M. Phung, S. Wouters and K. Pierloot, J. Chem. Theory Comput., 2016, 12, 4352-4361.

49 R. Christensen, H. A. Hansen, C. F. Dickens, J. K. Nørskov and T. Vegge, J. Phys. Chem. C, 2016, 120, 24910-24916.

F. Calle-Vallejo, J. I. Martínez, J. M. García-Lastra, E. Abad and M. T. M. Koper, Surf. Sci., 2013, 607, 47-53.

I. C. Man, H.-Y. Su, F. Calle-Vallejo, H. A. Hansen, J. I. Martínez, N. G. Inoglu, J. Kitchin, T. F. Jaramillo, J. K. Nørskov and J. Rossmeisl, Chem CatChem, 2011, 3, 1159-1165.

G. L. Miessler, P. J. Fischer and D. A. Tarr, Inorganic Chemistry. 5th edition, Pearson, Boston, 2014.

54 I. C. Man, H. Y. Su, F. Calle - Vallejo, H. A. Hansen, J. I. Martínez, N. G. Inoglu, J. Kitchin, T. F. Jaramillo, J. K. Nørskov and J. Rossmeisl, ChemCatChem, 2011, 3, 1159-1165.

55 K. Chan and J. K. Norskov, J. Phys. Chem. Lett., 2015, 6, 2663-2668.

56 Y.-H. Fang, G.-F. Wei and Z.-P. Liu, J. Phys. Chem. C, 2014, 118, 3629-3635.

57 Z. Duan and G. Henkelman, ACS Catal., 2019, 9, 5567-5573. 